\title{
Homework Habits Of College Physics Students
}

Paul M. Kotas, (E-mail: kotas@pa.msu.edu), Michigan State University Joseph E. Finck, (Email: Finck@phy.cmich.edu), Central Michigan University Mihai Horoi, (E-mail: horoi@phy.cmich.edu), Central Michigan University

\begin{abstract}
Several physics instructors at Central Michigan University have utilized Computer-Assisted Personalized Approach (CAPA) for homework in their courses. Student activity on CAPA is automatically recorded and logged into the system's files. These log files have been examined and student surveys have been conducted. An analysis of this data provides some insight into when students do homework and how this behavior relates to performance and demographic factors.
\end{abstract}

\section{Introduction}

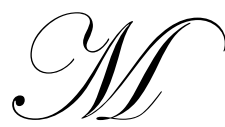

ost physics teachers would agree that problem solving, much of which is in the form of homework assignments, is an integral part of the learning process in physics courses. ${ }^{1}$ It is certainly reasonable, therefore, to expect that the manner in which students engage themselves with their physics homework is important. Although several studies over the decades seem to support what educators believe about the importance of homework, many of these studies are fairly limited, are highly dependent on student self-report, and pertain exclusively to K-12 levels. ${ }^{2}$

Recent integration of the Internet with the physics class has opened the door to directly observing students' homework behavior. At Central Michigan University (CMU), the Computer-Assisted Personalized Approach (CAPA) has been used in introductory physics courses to conduct homework over the Internet. CAPA was developed through a collaborative effort of the Physics-Astronomy, Computer Science, and Chemistry Departments at Michigan State University. ${ }^{3}$ This system allows instructors to create problem sets with variables that can be randomized and modified for each student. Thus each student receives an individualized problem set. When students submit answers they are given instant feedback and relevant hints. They may correct errors and resubmit their answers without penalty prior to the assignment due date. The system records the students' participation and performance in assignments, and reports are available on-line to both the instructor and individual students.

As a result of using CAPA in several courses at CMU, it was possible to examine the system's log files to gain insight into when students were doing their homework. First, we discuss the structure of the courses and identify general homework patterns. We then analyze homework behavior in relation to student achievement in physics. Finally, we look at demographic factors that may be involved with homework behavior.

\section{Description Of Course And Students}

Like other universities, Central Michigan University offers two full-year introductory courses that are significant department service courses. University Physics I and II are calculus-based courses. The students in College Physics I and II, the algebra based sequence, are the primary subjects of this study. The homework habits of students in three separate sections of College Physics have been examined. Data was initially collected for the 1998 spring semester College Physics II students when CAPA was first introduced at Central Michigan University. This course covers electricity, magnetism, optics, and modern physics. One hundred and ten students enrolled in the course. They all took and passed College Physics I which used traditional homework methods - typically five hand-graded problems a week. 
The second group studied was a 1998 fall semester College Physics I class consisting of 119 students. With the exception of three students who were repeating the course, this was their first college level physics experience. Preliminary data is also available for students presently enrolled in the 1999 spring semester College Physics II course - half of whom used CAPA in the College Physics I course. In all these courses the students were required to submit answers to their homework using CAPA. The data presented in this paper is primarily from the 1998 fall semester College Physics I course. In general, the results from the other two courses are quite similar.

The profile of students in introductory physics at CMU is probably similar to what one might find in a college physics course at many universities. Table 1 contains demographic and academic data for the students in the fall 1998 class. This information was obtained by examining student records available from the registrar and by conducting a demographics survey during the first week of class. Additionally, a study behavior survey was conducted at the end of the semester via the course website. Extra-credit encouraged survey participation, which was at or near the one hundred percent level for all surveys. The data collected in these surveys was analyzed to study potential factors related to the homework behavior observed.

Table 1. Demographics, Academic Information, And Technology Experience Survey Data For 119 Students In The Fall 1998 Semester.

\begin{tabular}{|c|c|c|c|c|c|c|}
\hline CLASS & $\begin{array}{c}36 \% \\
\text { Seniors }\end{array}$ & $\begin{array}{l}29 \% \\
\text { Juniors }\end{array}$ & $\begin{array}{c}26 \% \\
\text { Sophomores }\end{array}$ & $\begin{array}{c}10 \% \\
\text { Freshmen }\end{array}$ & $\begin{array}{l}\text { OFF-CAMPUS } \\
\text { RESIDENCE }\end{array}$ & $59 \%$ \\
\hline MAJOR & $34 \%$ Health & 27\% Biology & $\begin{array}{c}18 \% \\
\text { Technology } 4\end{array}$ & $\begin{array}{l}\text { 8\% Physical } \\
\text { Sciences }\end{array}$ & OWN COMPUTER & $55 \%$ \\
\hline MATH LEVEL & $\begin{array}{c}22 \% \\
\text { Algebra }\end{array}$ & $\begin{array}{c}36 \% \\
\text { Pre-calculus }\end{array}$ & $\begin{array}{c}42 \% \\
\text { Calculus }\end{array}$ & & $\begin{array}{c}\text { RESIDENTIAL } \\
\text { INTERNET ACCESS }\end{array}$ & $75 \%$ \\
\hline HS PHYSICS & $\begin{array}{l}67 \% \\
\text { Yes }\end{array}$ & $\begin{array}{c}33 \% \\
\text { No }\end{array}$ & & & $\begin{array}{l}\text { USE Web/E-Mail } \\
\text { WEEKLY }\end{array}$ & $68 \%$ \\
\hline GENDER & $\begin{array}{c}51 \% \\
\text { Female }\end{array}$ & $\begin{array}{l}49 \% \\
\text { Male }\end{array}$ & & & \multirow{2}{*}{$\begin{array}{c}\text { USED Web/E-Mail IN } \\
\text { OTHER COLLEGE } \\
\text { CLASSES }\end{array}$} & \multirow{2}{*}{$85 \%$} \\
\hline MEAN GPA & 3.1 & & & & & \\
\hline
\end{tabular}

Students were also given a set of "hour-by-day matrices" for their last three assignments. Students were asked to use these to log their study activity. The data from the self-report matrices and behavior survey were analyzed to determine the validity of using CAPA log data to measure homework behavior. While details will not be discussed here, the analysis suggests that the activity on CAPA is an accurate measure of when students did physics homework.

All three courses were organized into three-week segments over the fifteen-week long semesters. The first homework assignment involved simple math problems to give the students an opportunity to become acquainted with using CAPA. Subsequent assignments fell into a regular pattern. The first assignment of any three-week segment was based on the material covered in six lectures and typically involved solving twenty problems. It was distributed on a Wednesday and due a week-and-a-half later on Sunday at three in the morning. The second assignment of a three- week segment required the students to solve about fifteen problems based on four lectures. It was distributed on a Monday and due the following Sunday at three in the morning. Exams were held on Tuesdays, and the pattern repeated throughout the semester. The final grade in the course was based on homework submitted over the web using CAPA (40\%) and five exams $(60 \%)$. Several parameters must be kept in mind while examining the data collected in this study:

1. The class met Monday, Tuesday, Wednesday and Thursday mornings from 9:00 to 9:50.

2. The instructor's office hours were 10:00 to noon on Tuesday and Thursday, and 8:00 to noon on Friday.

3. The physics department at Central Michigan University provides a room for students to study during building hours (7:00 AM - midnight). This facility has computers with access to the web, and is staffed from 6:00 to 10:00 in the evenings of Monday through Thursday by undergraduate physics majors who are available to 
answer questions. Students are encouraged to work together and this room is a favorite gathering spot during the day and evening hours.

4. The homework was always due at 3:00 AM on Sunday. Odd homework assignments were distributed six days prior to the due date, and even homework assignments were given eleven days prior to the due date.

5. In order not to influence the homework habits of the students under study, results of this study from previous classes were not shared with the students. However, because of federal regulations associated with research involving human subjects, the students did know that their homework behavior was being observed.

\section{Homework Behavior And Performance}

This work describes how CAPA can be used to learn about the homework patterns of an individual instructor's students in a particular course. It is expected that different students in different courses will yield different results. However, there are similarities between the CMU students in these particular college physics courses and students at other universities in other physics and non-physics courses. These similarities suggest that general conclusions may be drawn regarding undergraduate homework behavior. For example, the data displayed in Fig. 1 is a histogram of all homework scores for the students in the fall 1998 semester College Physics I course at CMU. Similarly shaped curves and similar averages in courses using CAPA have been observed at Michigan State University in introductory calculus based physics classes, ${ }^{5}$ introductory chemistry lab and lecture classes, ${ }^{6}$ and botany classes. ${ }^{7}$ The results are also similar to those found in physics and chemistry courses at Hope College. ${ }^{8}$

Figure 1. Distribution Of All Homework Scores.

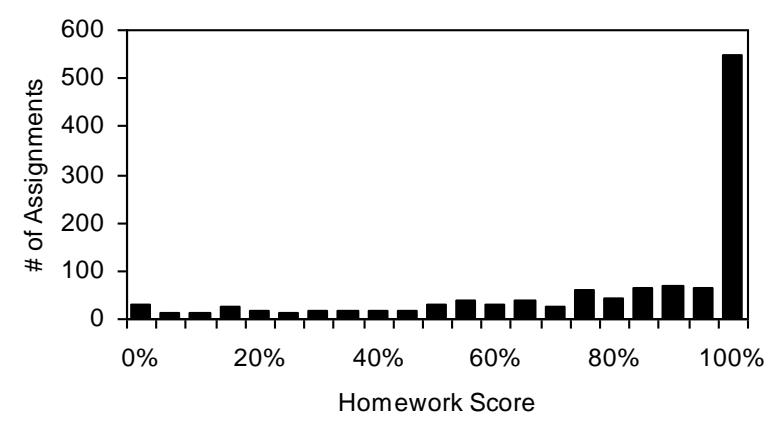

Forty-six percent of all scores were at the one hundred percent level.

The average score was eighty percent.

Every time a student submits an answer to CAPA the student is identified, the time and date of submission are recorded, and their answer is registered as correct, incorrect, wrong units, or wrong significant figures. Throughout this study, each of these submissions is called a "hit." Fig. 2a displays the total hits for the entire semester as a function of the day of the week. Recall that even problem sets are distributed eleven days before the deadline and odd problem sets are distributed on the Monday before the deadline. For the even sets, there is little activity prior to Monday. There is then an overall stead rise of homework activity during the days the class meets: Monday (4\%), Tuesday (10\%), Wednesday (19\%), and Thursday (22\%). This is followed by a drop on Friday (15\%). The busiest day is Saturday with almost a third of the total number of hits. There is an obvious attempt by students to complete their homework before the weekend. However, it is also clear that a large number of students wait until the last day to complete their assignments. Fig. $2 \mathrm{~b}$ shows when students first attempt each problem. The shape of the data is quite similar to the total hits. This is presented to show that the activity peak on Saturday is not due to a last frantic effort to finish the homework with multiple guesses. In fact, the Saturday activity is nearly exclusively due to problems started on Saturday. Throughout the semester it was observed that students tended to finish a problem the same day they started it. Fig $2 \mathrm{c}$ shows the final attempt on each problem and distinguishes between correct and incorrect final efforts. 
The data for the entire semester, which is displayed in Fig. 2, can be broken down by individual assignments. Fig. 3a shows the hit distributions for the first three assignments. Homework set 1 was distributed on the first day of class - a Monday — and due at 3 AM on the Sunday beginning the second week of classes. Many students appear to have been eager to start the assignment right away, and 70\% completed it by Thursday. Recall that simple math problems were asked in this assignment. The goal was to give the students an opportunity to become familiar with CAPA.

Figure 2. Distribution Of Hits By Day Of The Week

(a) Total Hits

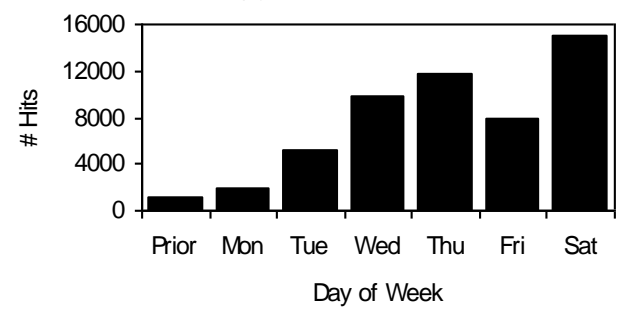

(b) First Attempts

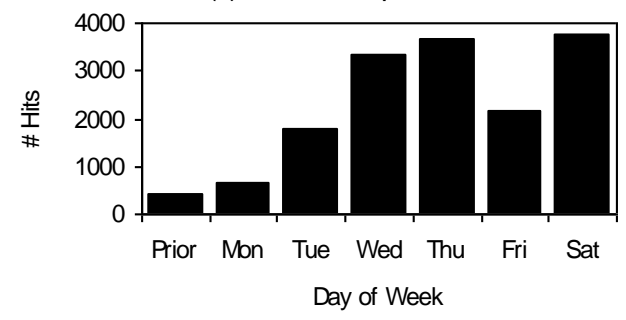

(c) Final Attempts

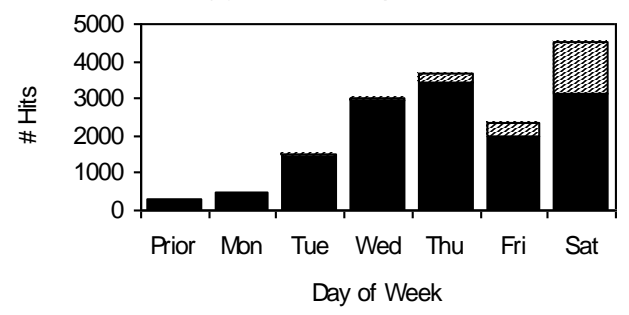

(a) shows the total hits for the semester. (b) shows first attempts for every problem.

(c) shows correct $(v)$ and incorrect $(/ /)$ ) final attempts for each problem.

Homework assignments were always due Sunday morning at 3:00 A.M

Homework set 2 was distributed on Wednesday of the first week of class and was due on the Sunday beginning the third week of classes. For this assignment homework activity rises exponentially as the deadline approaches. The hit pattern suggests that the easy first assignment may have lulled the students into believing that the homework would not be difficult. By the third assignment hit distributions similar to Fig. 2 begin to emerge. Fig. $3 \mathrm{~b}$ illustrates the progression of all eleven assignments in terms of average sco

re and average day that homework was done. It is evident that there was a shift in homework behavior after mid-term grades were reported. In addition, a strong correlation exists $(r=-.77)$ between the average day and performance on assignments, showing that when students did their homework earlier the result was a better score. 
In Fig. 4 the hit data for the semester is presented for each hour of the day. Some might have expected there to be substantial activity after midnight. However, the data indicate that the most active times are when assistance is available. Twenty-seven percent of all hits fall between 6:00 and 10:00 in the evening when tutors are available in the study room. Almost ten percent of the hits occur during the hour following class (10:00 AM). There is also substantial activity on Friday morning. Recall that the instructor held office hours on Friday morning from 8:00 to noon.

Figure 3

(a)

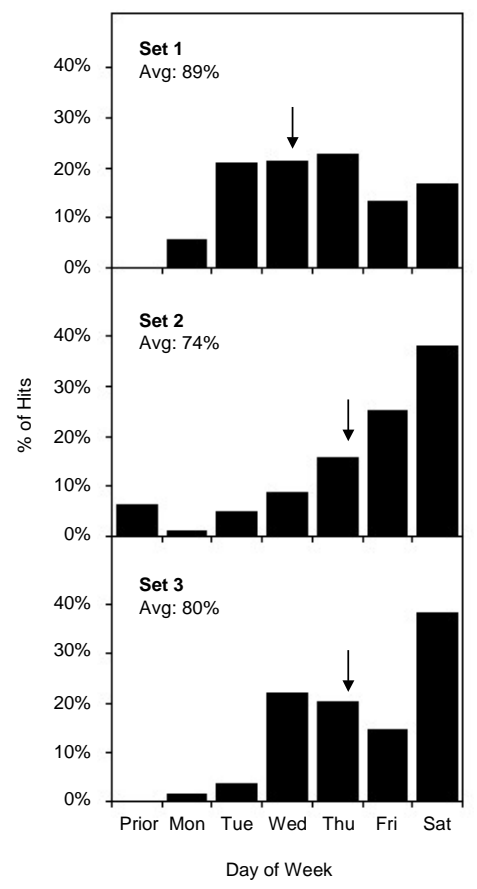

(b)

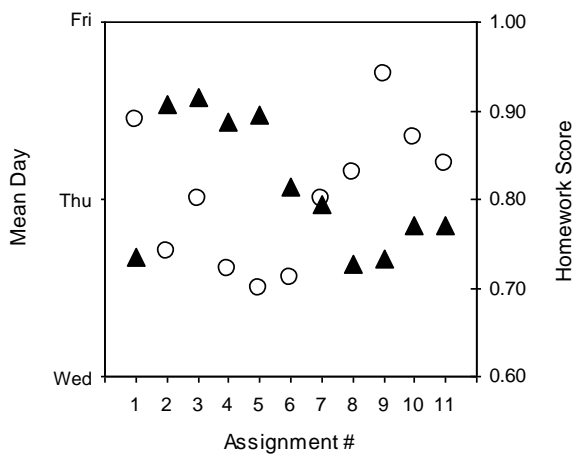

(a) Distribution of total hits for the first three assignments.

The arrows indicate the mean day which homework was done.

(b) illustrates for each assignment the average score (0) and mean day which homework was done $(\boldsymbol{\Lambda})$. The observed shift in these two correlated values occurs after mid-term grades are reported.

The 10:00 AM peaks are particularly impressive, considering that this is a popular time for students to schedule classes other than physics. Two-thirds of the class contributed to these peaks, one-third on a regular basis. It is interesting to note that this third of the students achieved significantly higher final course grades $(79 \%)$ than the rest of the students (67\%). The most popular single hour of the week was the hour immediately following the last lecture of the week. The 10:00 AM peaks are also interesting because of their presence in the 1998 spring semester data. Although the instructor did not hold the same office hours that semester, 10:00 AM on Thursday was still the most popular hour for doing homework. It was upon this discovery that the instructor had set new office hours for the following semester to coincide with this period of high activity. 
Figure 4

(a) Total Hits by Hour

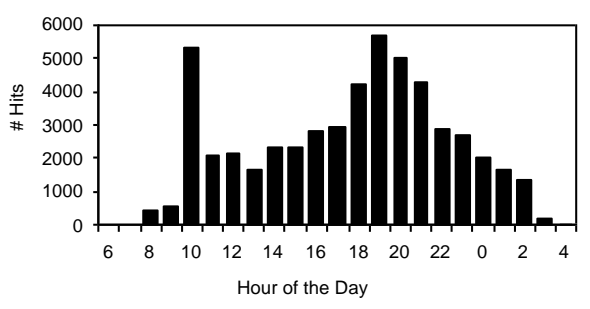

(b) Total Hits by Hour by day

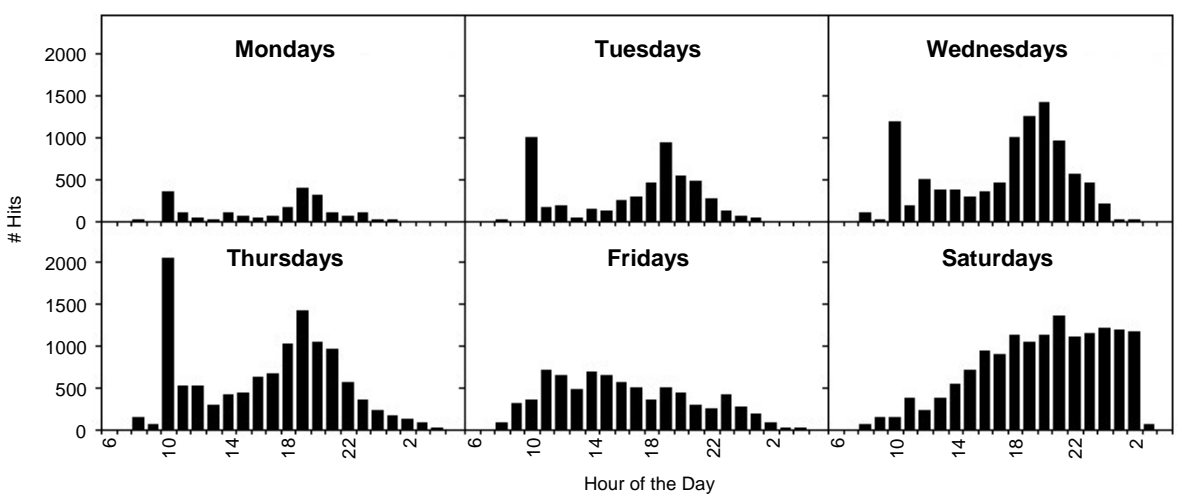

(a) Distribution of total hits by hour of the day.

(b) Hourly distribution by day of the week.

10:00 A.M. was the hour immediately following lecture.

Thus far, we have only presented homework activity for the entire class. With the information available from the registrar and the surveys and the students' performance in class, it was possible to identify common characteristics of the students that correlate with the homework patterns. The most significant relationship was observed to be between homework behavior and students' final grade in the course. Fig. 5 shows the hit patterns for five groups that are based on final grade. The top twenty-five percent of the class is the 1st quarter group, while the bottom twenty-five percent constitutes the 4th quarter group. CMU has a policy that allows student to withdraw from a course through the tenth week. The seventeen students who, at some point in the semester, withdrew from the class make up the fifth group labeled "W." The result of this analysis is dramatic. Fig. 5 clearly shows that those who received the highest grades in physics started and did most of their work well before the deadline, while those who performed poorly procrastinated. Students in the top half of the class submitted seventy-five percent of their total hits by Thursday. Forty-one percent of the hits from the students in the bottom quarter occurred on Saturday, and students who ended up withdrawing did nearly sixty percent of their work on the last day. 
Figure 5

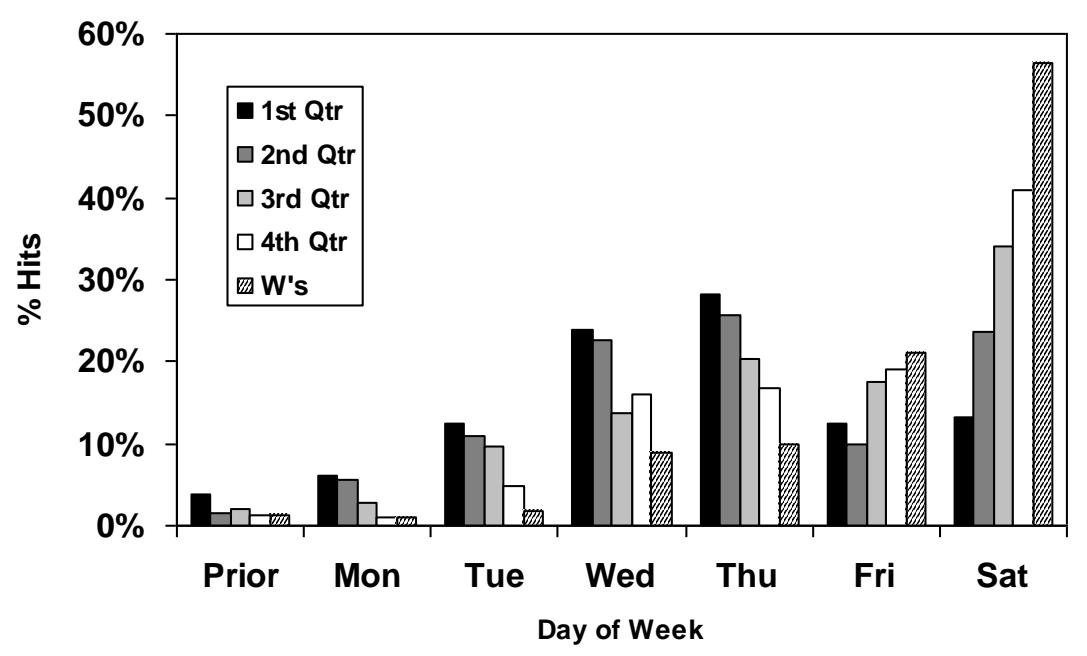

Normalized distribution of hits for five separate groups of students based on final grade. The top twenty-five percent of the students constitute the 1st quarter group. The W-group represents the students who withdrew from the course.

In order to analyze the significance of the differences in the hit distributions, it is necessary to represent the data in terms of individual statistics. For example, a student's "Day-Mean" value is computed by averaging the "days" for all of that student's hits. As Fig. 6a illustrates, there is a significant correlation between students' performance and the mean day for which homework was done. It is evident that there were a handful of students who procrastinated and still did well in the course; however, most of the top students did their homework earlier in the week. There are also a handful of students who exhibited good homework practice and did not perform well; however, most of the 4th quarter students did homework late in the week. When Day-Mean values are grouped by quarters, the results from analysis of variances indicate that significant differences $(\mathrm{p}<.001)$ exist between the best students and the bottom half of the class, and between the 4th quarter students and the top half of the class.

The Day-Mean value partially gives a flavor of when students are doing homework. One may also be interested in the extent to which students do homework on a daily basis. A student's "Day-Spread" value is a measure of how much a student spreads his work out over the week. A student who achieves a Day-Spread value of 2.0 for a particular assignment, for example, has done half of the work (hits) on one day, and half on another day (regardless of which days). In Fig. 7, the students' mean Day-Spread values over ten assignments are plotted against their Day-Mean values. The correlation is significantly high, and the data strongly suggests that those who did well not only worked on their assignments earlier, but also spread their work out during the week. The graph shows that some of the better students worked on their homework early in the week, but had rarely taken more than a day or two to get it done. However, a majority of the students who did well achieved higher Day-Spread values, indicating that they were more engaged in their physics homework. 


\section{Figure 6}

(a)

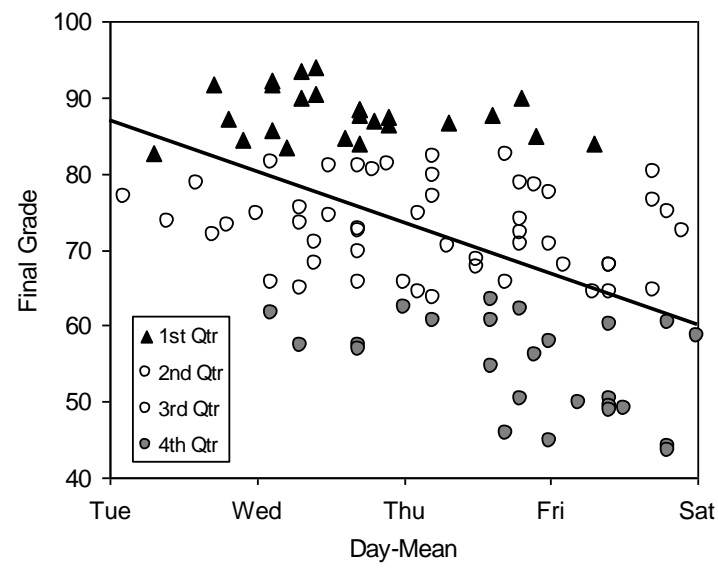

(b)

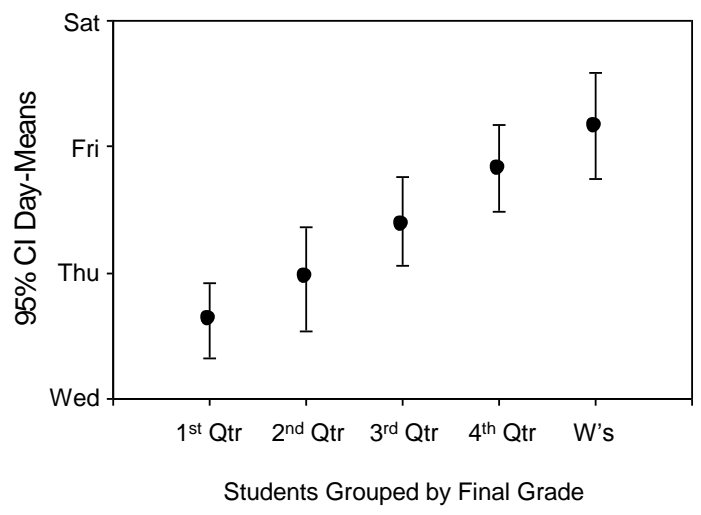

(a) shows the mean day for which each student did homework.

Most 1st Quarter students did homework earlier in the week, while most 4th students tended to procrastinate.

(b) shows the mean Day-Mean value with 95\% confidence interval for each quarter group and the withdrawal group.

Figure 7

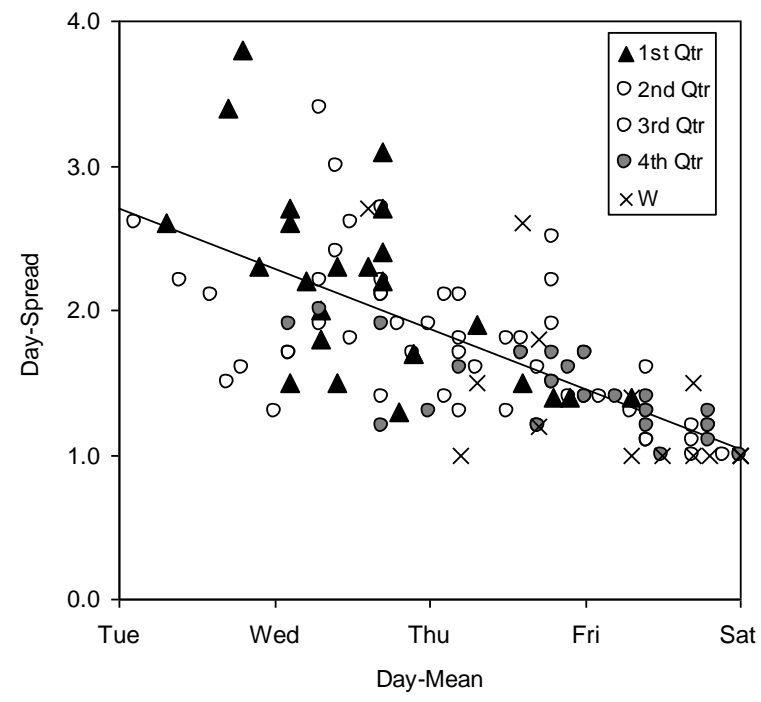

Here each student's Day-Mean value is plotted against his/her mean Day-Spread value over ten assignments. Higher Day-Mean values inherently require lower Day-Spread values. However, the data indicates that many of the top students had spread their work over several days out of the week. 


\section{Factors Involved With Homework Behavior}

A relationship between homework behavior and performance in the course has clearly been established. This relationship was observed in the 1998 spring semester College Physics II course as well, and appears to be present in several courses currently being taught. A more difficult task would be to determine what factors, if any, may be related to homework behavior. One immediate factor that may be analyzed is students' access to the Internet. It is very conceivable that this could be a factor, since the students who own a computer seem to have more flexibility in submitting their answers. An analysis of the data, however, shows no difference in the hit patterns between the students who had residential Internet access and those who did not. In addition, there was no difference in the performance between these two groups of students. This example is illustrated here to show what may be expected from the results of Fig. 5 . Generally, when a difference in homework behavior was found to exist between groups of students, there was a corresponding difference in the final grades, even when the differences were not statistically significant.

Residence, computer experience, Internet availability, mathematics preparation, and high school physics experience did not appear to affect homework behavior or performance. However, class and curriculum did appear to be factors. Sophomores achieved the highest grades in the course, while freshmen scored significantly lower. Indeed, this is what the reader would expect when observing the hit distributions in Fig. 8. A similar relationship exists between homework patterns and final grades when considering students' academic fields. Students enrolled in the health and physical sciences exhibited the best homework behavior and achieved above average final grades, while the industrial engineering technology students tended to procrastinate and consequently scored very low. The CAPA data from the previous course shows similar results for both the class and curriculum factors.

Figure 8: Normalized Hit Distributions By Class

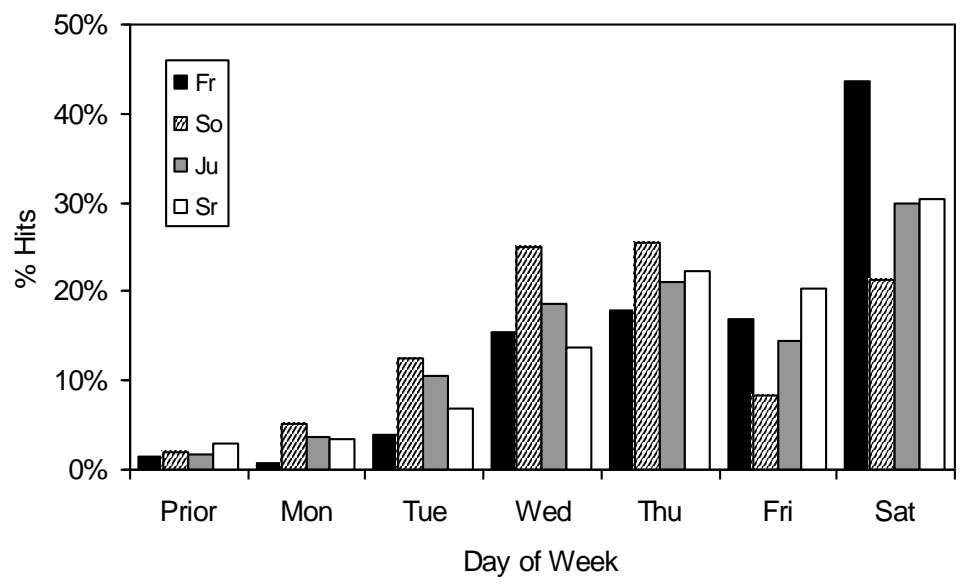

Sophomores achieved the highest grades in the class, while freshmen did significantly worse.

The most interesting factors observed in this study, however, were collaboration on assignments, gender, and students' grade point average. One survey question asked the students about working on their homework with other students. The degree to which students worked in study groups was related to the hit distributions in almost the same fashion as observed in Fig. 5. Students who reported never having worked with other students tended to be procrastinators, while those students who always collaborated did their homework in a timely manner and did well in the course. Numerous studies have shown the importance of collaboration among students in enhancing the learning process. ${ }^{9}$ 
Fig. 9 shows the hit distributions by gender for two separate classes. For the fall 1998 class, there is a significant difference in homework behavior between males and females, as well as a corresponding difference in final grades. Although females significantly outperformed males in the Fall 1998 course, gender differences did not appear in the previous semester. There are several issues that would account for the difference observed in our data. Foremost, females in the fall 1998 semester were found to work in study groups much more than males. Additionally, females in this sample tended to be younger (sophomores \& juniors) and were found mostly to be in health science, while males dominated the industrial engineering technology and freshmen groups.

Significant relationships $(\mathrm{p}<.001)$ were also found when homework behavior and achievement in physics were analyzed with students' GPA data. Not only were Day-Mean and Day-Spread values correlated to final grades in physics, they were also correlated $(r=.5)$ to cumulative GPA prior to entering the course. More interestingly, homework behavior and physics grades were significantly correlated $(r=.4)$ to the adjusted semester GPA which had physics grades factored out. This immediately suggests a possible relationship between homework behavior in physics and homework behavior in other courses.

Figure 9. Normalized Hit Distributions By Gender For Two Separate Classes

(a)

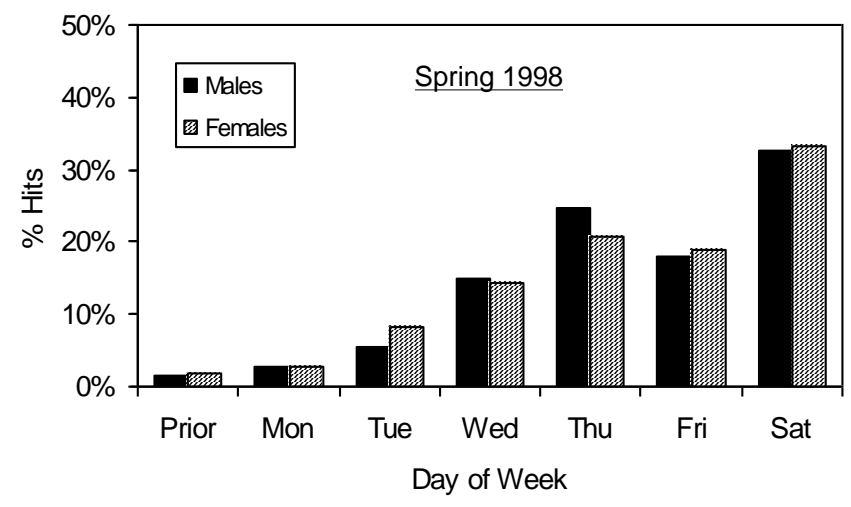

(b)

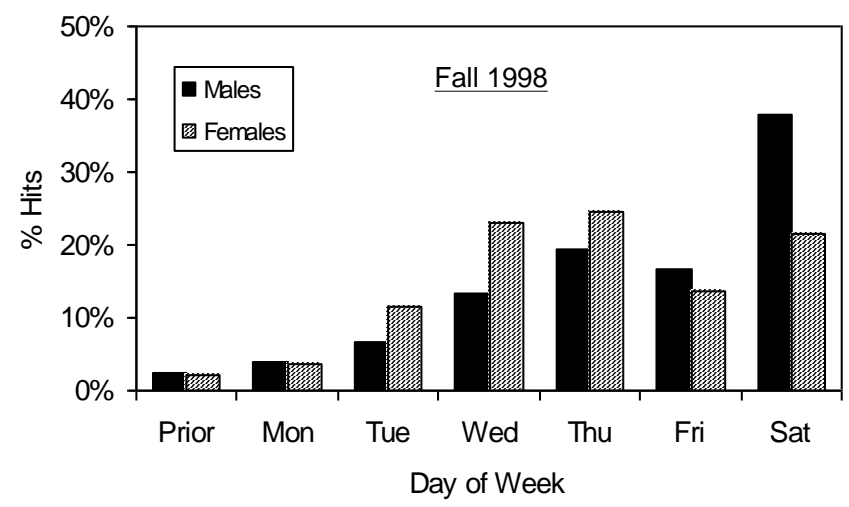

(a) shows that for the spring 1998 sample, there was no difference in when males and females did homework. Also, there was no difference in final grades.

(b) illustrates a significant difference in homework behavior. For this sample, females achieved significantly higher final grades. 


\section{Conclusions And Outlook}

Over the past three semesters the Computer Assisted Personalized Approach has been used as a tool for homework assignments in non-calculus introductory physics courses at Central Michigan University. This study shows that since CAPA records the time when students submit answers, it can be used by instructors as an instrument to determine when their students are working on assignments. This information can be used by instructors to set office hours at times when their students are likely to have questions, and departments can determine the best times to open rooms which may be used by students to work collaboratively on their assignments. This examination of student homework habits may also be extended to the other disciplines (chemistry, biology, mathematics, and food science) using CAPA as an instructional tool.

The students involved in this study had at least six days to work on their assignments, which were always due on Sunday at three in the morning. The data showed homework activity increasing from Monday through Thursday as many students attempted to finish their assignments before the weekend. Friday showed a drop in activity, but Saturday—just before the deadline — was the busiest day of the week. Several significant features were observed when daily data was examined by hour. Activity is substantial when assistance is available, and there is little work done in the wee hours of the morning. The most striking result is the activity at ten in the morning - the hour following class. The existence of the prominent Thursday 10:00 AM peaks in all semesters suggests that many students use the time immediately following lecture as a last opportunity to work in their study groups before the weekend.

Analyzing this data with academic information convincingly shows that the majority of students who earned high grades in college physics started and completed their homework early, while most students who procrastinated on their assignments received the lowest grades in the class. The analysis also shows that students who performed well tended to spread their work out over several days, as opposed to their counterparts who spent less time on assignments.

There was no correlation between homework habits and residence, computer experience, Internet availability, mathematics preparation, or high school physics experience. Likewise, these factors did not appear to affect final grades. Sophomores and students in the health and physical sciences did exhibit better homework behavior and the physics grades for these groups were above average. At CMU it has been noted that historically students enrolled in the very competitive Pre-Physical Therapy program tend to do better in physics. Although it is possible to draw conclusions about the factors of class and curriculum at CMU, these cannot be made general for students in other environments. Certainly, the results for gender warrant further investigation. While a gender gap existed in one semester and not the other, it appears that the contrast could be explained by homework behavior. It would be worthwhile to examine the data generated by larger samples of students using CAPA. It would also be interesting to compare the homework habits of college and university physics courses at an institution with an engineering program.

Can students become better learners with a change in homework behavior, or is it just that better students simply do their homework in a more timely manner? Is a student's homework behavior in physics similar in other classes? The results of this study show that not only did homework behavior in physics correlate to achievement in physics, it also correlated to overall performance at the university. Although improvements in physics education can provide a better learning experience for the physics student, it remains for the student to have the willingness to learn.

${ }^{1}$ E. Kashy, B.M. Sherrill, and Y. Tsai, “CAPA, an integrated computer assisted personalized assignment system,” Am. J. Phys. 61(12), 1124-1130 (1993).

2 S. Ziegler, "Homework," Encyclopedia of Educational Research, 6th Ed.

3 E. Kashy, D.J. Morrissey, and Y. Tsai, "An introduction to CAPA, a versatile tool for science education," MSU-NSCL Report 971, September 1995.

4 The Industrial and Engineering Technology (IET) curriculum offers a broad knowledge of applied industrial arts and technologies and prepares students for industrial careers in a variety of technical, supervisory, or managerial capacities, or teaching certification. Engineering Technology at CMU is not a professional engineering program.

5 M. Thoennessen and M. J. Harrison, "Computer-assisted assignments in a large physics class," Computers Educ. 27, 
141 (1996).

6 P. Hunter, "Issues in a 2000-student chemistry course," presented at a CAPA workshop, Lansing MI, 27 February 1999 (unpublished).

7 K. Nadler, "Implementation and results in botany," presented at a CAPA workshop, Lansing MI, 27 February 1999 (unpublished).

8 C. Mader and G. Peaslee, "CAPA 4.6 and DISCUS at Hope College," presented at a CAPA workshop, Lansing MI, 27 February 1999 (unpublished).

9 U. Treisman, "Studying students studying calculus," The College Math. J. 23, 362 (1992).

Notes 